\title{
PENGARUH EKSTRAK TANAMAN SEBAGAI SUMBER ZPT ALAMI TERHADAP PERTUMBUHAN SETEK TANAMAN LADA (Piper nigrum L.)
}

\section{(The Effect some crop extract as natural ZPT towards pepper cutting growth (Piper nigrum L.))}

\author{
Abdullah*, Maulana Wulandari* ${ }^{*}$, Nirwana* \\ "Program Studi Agroteknologi Fakultas Pertanian Universitas Muslim Indonesia \\ Corresponding author: abdullah.abdullah@umi.ac.id dan maulanawulandari3@gmail.com \\ ${ }^{* *}$ Alumni Program Studi Agroteknologi Fakultas Pertanian Universitas Muslim Indonesia
}

\begin{abstract}
The purpose of research is to view the effect some crop extract as natural growth hormon towards pepper cutting growth, conduted in Bontomanai District of Selayar Island Regeny, during March - May 2018. This experimental research used random group of environmental design by one factor treatment, without Growth hormone submersion, coconut water 50\%, red onion extract 75\%, moringa leaves extract $30 \%$, sargassum seaweed extract 25\%, cow urine 15\%, and Growtone 12,5\%. The data was analyzed based on the F (ANOVA) test and contrast test. Growth hormone Growtone using is better than compared to coconut water, red onion, moringa leaves, sargassum seaweed and cow urine in responding, peper cutting growth. Red onion extract $75 \%$ is better than moringa leaves extract and sargassum seaweed extract towards to components of pepper cuttings growth (budding period, number of buds, bud length, root volume and the percentage of living cuttings) coconut water 50\% has effect on budding period of pepper cuttings and cow urine $15 \%$ has effect on leaf wide. Sargassum extract $25 \%$ has effect on number of leaves and leaf wide.
\end{abstract}

Keywords : Crop Extract, Natural, Growth hormone, Pepper, Cuttings

PENDAHULUAN

Tanaman lada (Piper nigrum L) merupakan salah satu komoditas perkebunan bernilai ekspor urutan keenam dengan total 58.075 ton dengan nilai 548.193 US\$. Luas areal perkebunan tanaman lada pada tahun 2017 (167.626 ha) menurun jika dibandingkan tahun 2016 (168.080 ha). Namun, produksinya meningkat (82.674 ton) dibandingkan tahun 2016 (82.167 ton) (Statistik Perkebunan Indonesia, 2015-2017).

Peningkatan produksi lada masih perlu dilakukan karena akan berdampak terhadap pendapatan petani dan devisa negara. Untuk mencapai produktivitas secara optimal perlu perbaikan sistem budidaya secara efektif, efisien dan ramah lingkungan. Salah satu diantara adalah penggunaan bibit berkualitas.

Penyediaan bibit berkualitas dapat diperoleh melalui perbanyakan setek. Menurut Amanah (2009), pembiakan melalui setek dapat mengatasi ketersediaan bibit secara cepat dan mendukung peningkatan produksi. Namun demikian, factor penghambat keberhasilan pertumbuhan setek adalah 
pembentukan akar (adventif) dan tunas yang lambat pada setek. Untuk mengatasi hal tersebut dapat digunakan zat pengatur tumbuh (ZPT) alami maupun buatan.

Menurut Wattimena (2000) hormon tumbuh atau fitohormon adalah senyawa organik yang terbentuk secara alami maupun buatan dan dapat mempengaruhi partumbuhan serta perkembangan tanaman. Hormon tumbuh alami dapat diekstrak dari berbagai jenis tanaman dan dapat digunakan sebagai pemacu pertumbuhan setek.

Berdasarkan informasi penelitian tersebut di atas, maka penelitian ini bertujuan untuk mengetahui pengaruh beberapa ekstrak tanaman terhadap pertumbuhan setek lada. Ekstrak tanaman dapat menjadi alternatif sumber ZPT alami dan ramah lingkungan bagi perbanyakan tanaman lada secara setek.

\section{METODE PENELITIAN}

Penelitian ini dilaksanakan di Kecamatan Bontomanai Kabupaten Kepulauan Selayar mulai Maret - Mei 2018.

Penelitian eksperimental ini menggunakan rancangan lingkungan acak kelompok dengan perlakuan yakni:

1. $\mathrm{K}=$ Tanpa perendaman $\mathrm{ZPT}$
2. $\mathrm{AK}=$ Air Kelapa $50 \%$

3. $\mathrm{BM}=$ Ekstrak bawang merah $75 \%$

4. $\mathrm{DK}=$ Daun Kelor $30 \%$

5. $\mathrm{SR}=$ Ekstrak sargassum $25 \%$

6. US = Urine sapi $15 \%$

7. $\mathrm{GT}=$ Growtone $12,5 \%$

Masing-masing perlakuan menggunakan 10 setek tanaman lada dan diulang 3 kali. Data dianalisis uji F (ANOVA) dan uji kontras. Perbandingan uji kontras yang direncanakan, yaitu :

1. K Vs AK, BM, DK, SR, US, GT

2. GT Vs AK, BM, DK, SR, US

3. US Vs AK, BM, DK, SR

4. AK Vs BM, DK, SR

5. BM Vs DK, SR

\section{DK Vs SR}

Setek ditanam dalam media tanah, pasir dan pupuk kandang perbandingan 2:1:1 (v/v). Air kelapa yang digunakan dari kelapa muda segar (100\%) lalu diencerkan menjadi konsentrasi 50\%, dengan cara $500 \mathrm{ml}$ air kelapa muda ditambahkan $500 \mathrm{ml}$ aquades.

Ekstrak bawang merah dibuat dari 1 $\mathrm{kg}$ umbi bawang merah dihaluskan dan disaring sebagai larutan 100\%. Pembuatan larutan $75 \%$ dengan cara $750 \mathrm{ml}$ ekstrak bawang merah ditambah $250 \mathrm{ml}$ aquades.

Ekstrak daun kelor dibuat dari $1 \mathrm{~kg}$ daun kelor ditambahkan 1 liter aquades 
dan di blender hingga membentuk pasta, tanah, pasir dan pupuk kandang kemudian diperas dan disaring. perbandingan 2:1:1 (v/v) dengan cara Pembuatan larutan $40 \%$ dilakukan dengan setek dibenamkan sedalam $5 \mathrm{~cm}$ hingga cara $300 \mathrm{ml}$ ekstrak daun kelor $+700 \mathrm{ml}$ batas buku pertama dari dua buku setek aquades. yang digunakan. Untuk menjaga

Ekstrak rumput laut sargassum dibuat dengan cara memblender rumput laut kelembaban media dilakukan penyiraman dan penyungkupan hingga setek berumur dalam aquades perbandingan 1:1. \pm 2 bulan..

Selanjutnya dipanaskan pada suhu $40^{\circ} \mathrm{C}$

Pengamatan dilakukan mulai 2 mst selama 15 menit, lalu didinginkan dan hingga 12 mst dengan interval 2 minggu disaring. Hasil saringan yang diperoleh sekali. Parameter pengamatan: waktu sebagai larutan 100\% (Kusmaningrum et al., 2007). Pembuatan larutan $25 \%$ dengan cara $250 \mathrm{ml}$ ekstrak ditambahkan $750 \mathrm{ml}$ aquades.

Urine sapi ditampung langsung dari hewan sapi dan didiamkan beberapa saat. Larutan urine sapi 15\% dibuat dengan cara $150 \mathrm{ml}$ urine sapi $+850 \mathrm{ml}$ aquades Growtone merupakan ZPT buatan dan digunakan sebagai pembanding dengan konsentrasi $12,5 \% \quad(12,5 \quad \mathrm{~g}$ dilarutkan dalam $850 \mathrm{ml}$ aquades).

Bahan setek lada diambil dari cabang orthotrop yang sehat dan pertumbuhan baik serta tidak dalam kondisi berbunga atau berbuah. Setek yang digunakan 2 buku, setek direndam dalam ekstrak ZPT alami selama 12 jam dan pencelupan dalam Growtone selama 2 menit. Setek ditanam dalam polybag berisi media bertunas, jumlah tunas, panjang tunas, jumlah daun, luas daun, panjang akar, volume akar dan persentase setek tumbuh.

\section{HASIL DAN PEMBAHASAN}

\section{a. Hasil Penelitian}

Hasil penelitian dan uji statistik menunjukkan bahwa penggunaan berbagai ekstrak tumbuhan sebagai sumber zat pengatur tumbuh terhadap setek tanaman lada berpengaruh nyata terhadap parameter waktu bertunas, jumlah tunas, panjang tunas, jumlah daun dan luas daun (Tabel 1).

Hasil analisis uji kontras orthogonal (Tabel 1) menunjukkan bahwa dari berbagai perbandingan yang telah direncanakan hanya dua perbandingan yang memperlihatkan pengaruh yang nyata secara konsisten terhadap semua 
parameter pertumbuhan bagian atas yang US) dan BM vs (DK, SR).

diamati, yaitu: GT vs (AK, BM, DK, SR,

Tabel 1. Hasil uji kontras ortogonal pertumbuhan bagian atas setek tanaman lada dari berbagai ekstrak tanaman sebagai sumber zat pengatur tumbuh

\begin{tabular}{|c|c|c|c|c|c|}
\hline Pembanding Ortogonal & $\begin{array}{l}\text { Waktu } \\
\text { Bertunas }\end{array}$ & $\begin{array}{l}\text { Jumlah } \\
\text { Tunas }\end{array}$ & $\begin{array}{c}\text { Panjang } \\
\text { Tunas }\end{array}$ & $\begin{array}{l}\text { Jumlah } \\
\text { Daun }\end{array}$ & $\begin{array}{l}\text { Luas } \\
\text { Daun }\end{array}$ \\
\hline K Vs (AK, BM, DK, SR, US, GT) & $8,73^{*}$ & $0,37^{\mathrm{tn}}$ & $15,03^{\text {*** }}$ & $2,63^{\text {tn }}$ & $0,48^{\mathrm{tn}}$ \\
\hline GT Vs (AK, BM, DK, SR, US) & $18,76^{* *}$ & $18,78^{* *}$ & $26,67^{* *}$ & $26,52^{* *}$ & $11,69^{* *}$ \\
\hline US Vs (AK, BM, DK, SR) & $1,18^{\text {tn }}$ & $4,26^{\mathrm{tn}}$ & $0,72^{\mathrm{tn}}$ & $2,08^{\mathrm{tn}}$ & $12,76^{\text {*** }}$ \\
\hline AK Vs (BM, DK, SR) & $30,55^{* *}$ & $3,62^{\text {tn }}$ & $0,02^{\text {tn }}$ & $0,39^{\mathrm{tn}}$ & $0,001^{\mathrm{tn}}$ \\
\hline $\begin{array}{l}\text { BM Vs (DK, SR) } \\
\text { DK Vs SR }\end{array}$ & $\begin{array}{c}41,18^{* *} \\
1,02^{\text {tn }}\end{array}$ & $\begin{array}{l}8,77^{*} \\
0,22^{\text {tn }}\end{array}$ & $\begin{array}{r}15,00^{* * *} \\
1,13^{\mathrm{tn}}\end{array}$ & $\begin{array}{c}24,77^{\text {** }} \\
4,83^{*}\end{array}$ & $\begin{array}{r}32,63^{* * *} \\
4,82^{*}\end{array}$ \\
\hline
\end{tabular}

Hormon tumbuh buatan Growtone pertumbuhan bagian atas setek tanaman masih lebih baik dan efektif dalam lada.

merespon pertumbuhan setek tanaman

lada jika dibandingkan dengan ekstrak

tanaman dan urin sapi. Selanjutnya

ekstrak bawang merah (BM) jika

dibandingkan dengan daun kelor (DK)

dan sargassum (SR) secara konsisten

menunjukkan pengaruh lebih baik stek tumbuh. Namun, berpengaruh tidak terhadap semua komponen pengamatan nyata terhadap volume akar (Tabel 2).

Tabel 2. Hasil uji kontras ortogonal pertumbuhan bagian bawah stek tanaman lada dari berbagai ekstrak tanaman sebagai sumber zat pengatur tumbuh

\begin{tabular}{lccc}
\hline \hline \multicolumn{1}{c}{ Pembanding Ortogonal } & $\begin{array}{c}\text { Panjang } \\
\text { Akar }\end{array}$ & Volume Akar & Persentase Stek Hidup \\
\hline \hline K Vs (AK, BM, DK, SR, US, GT) & $0,45^{\text {tn }}$ & $0.06^{\text {tn }}$ & $0,93^{\text {tn }}$ \\
GT Vs (AK, BM, DK, SR, US) & $15,09^{* *}$ & $6.74^{*}$ & $11,73^{* *}$ \\
US Vs (AK, BM, DK, SR) & $3,65^{\text {tn }}$ & $0.05^{\text {tn }}$ & $1,54^{\text {tn }}$ \\
AK Vs (BM, DK, SR) & $1,21^{\text {tn }}$ & $0.99^{\text {tn }}$ & $0,64^{\text {tn }}$ \\
BM Vs (DK, SR) & $36,82^{* *}$ & $7.04^{*}$ & $9,74^{\text {** }}$ \\
DK Vs SR & $0,62^{\text {tn }}$ & $0.33^{\text {tn }}$ & $0,24^{\text {tn }}$ \\
\hline
\end{tabular}

Keterangan : $* *=$ Berbeda sangat nyata pada taraf $1 \% ; *=$ Berbeda nyata pada taraf $5 \% ;$ th $=$ Berbeda tidak nyata. 
Hasil analisis uji kontras orthogonal (Tabel 2) menunjukkan bahwa dari berbagai perbandingan yang telah direncanakan hanya dua perbandingan yang memperlihatkan pengaruh yang nyata secara konsisten terhadap semua parameter pertumbuhan bagian bawah (panjang akar, volume akar dan persentase stek hidup) yang diamati, yaitu: GT Vs (AK, BM, DK, SR, US) dan BM Vs (DK, SR). Pola pengaruh antara bagian atas dan bawah tanaman lada adalah sama.

Pengaruh Hormon tumbuh buatan Growtone masih lebih baik dan efektif dalam merespon pertumbuhan bagian bawah setek tanaman lada jika dibandingkan dengan ekstrak tanaman dan urin sapi. Selanjutnya ekstrak bawang merah (BM) jika dibandingkan dengan daun kelor (DK) dan sargassum (SR) secara konsisten menunjukkan pengaruh lebih baik terhadap semua komponen pengamatan pertumbuhan bagian atas setek tanaman lada.

\section{b. Pembahasan}

Berdasarkan hasil penelitian dan uji statistik yang telah dilakukan menunjukkan bahwa penggunaan berbagai ekstrak tumbuhan sebagai sumber zat pengatur tumbuh terhadap setek tanaman lada berpengaruh nyata ( $\alpha$ 1\%) terhadap komponen partumbuhan: waktu bertunas, jumlah tunas, panjang tunas, jumlah daun, luas daun dan panjang akar dan berpengaruh nyata ( $\alpha$ 5\%) terhadap persentase setek hidup. Sedangkan terhadap volume akar berpengaruh tidak nyata baik pada $\alpha 5 \%$ dan $\alpha 1 \%$.

Hasil ini memberikan indikasi bahwa penggunaan berbagai ekstrak tanaman dapat sebagai hormon tumbuh alternatif dalam perbaikan pertumbuhan setek tanaman lada. Menurut Nurlaeni dan Surya (2015), ZPT alami yang bersumber dari ekstrak tanaman dapat menjadi alternatif dan mudah diperoleh, relatif murah dan aman digunakan serta lebih ramah lingkungan. Hal ini menunjukkan bahwa dalam ekstrak tanaman mengandung unsur atau komponen hormon tumbuh selain unsur lainnya, seperti hara, vitamin dan lainnya.

Hasil ini didukung oleh beberapa penelitian tentang penggunaan ekstrak tanaman dalam merespon pertumbuhan tertentu tanaman. Beberapa ekstrak tanaman yang telah banyak digunakan sebagai hormon tumbuh alami diantaranya ekstrak tomat, ekstrak kecambah tauge (Rahmad, 2015), ekstrak rumput laut sargassum (Wahyudi, 2016), ekstrak jagung muda, ekstrak bonggol pisang. ZPT alami dari ekstrak bawang merah 
sebagai sumber auksin, rebung bambu sebagai sumber giberelin, dan bonggol pisang serta air kelapa sebagai sumber sitokinin (Lindung, 2014).

Namun, penggunaan Growtone masih lebih baik jika dibandingkan dengan ekstrak tanaman. Hal ini sesuai hasil penelitian yang diperoleh bahwa Growtone dapat meningkatkan dan memperbaiki semua komponen pertumbuhan (waktu bertunas, jumlah tunas, panjang tunas, jumlah daun, luas daun, panjang akar, jumlah akar, volume akar dan persentase stek hidup) jika dibandingkan dengan air kelapa, ekstrak bawang merah, daun kelor, sargassum dan urin sapi.

Growtone merupakan zat pengatur tumbuh buatan mengandung bahan aktif dari kelompok hormon auksin seperti: Naftalena asetat $0,067 \%$, metil-1 naftalena setamida $0,013 \%$, metil-1 naftalena asetat $0,033 \%$, idol-3 butirat $0,05 \%$ dan thiram 4\%. (Kusumo, 1990; Hanriyanto, 2007 dalam Bukori, 2011). Selain itu, menurut Hanriyanto (2007) dalam Bukori (2011), Growtone mengandung fungisida yang berfungsi menekan kematian bibit akibat jamur saat pemindahan ke lapangan dan mengandung hormon tumbuh yang berfungsi merangsang pertumbuhan bibit (stump, setek, cangkok) serta dapat merangsang atau mempercepat pertumbuhan akar.

Hormon tumbuh buatan Growton memiliki kandungan hormon dan unsur lainnya yang telah diatur, terukur dan jelas kandungannya sehingga responnya terhadap tanaman lebih efektif dan nyata terlihat. Pada sisi lain ekstrak tanaman bukan dalam bentuk senyawa murni akan tetapi terdiri atas beberapa senyawa dan bersifat labil yang dapat berubah. Perubahan pada ekstrak tanaman dapat terjadi pada saat ekstraksi dan penerapannya. Sehingga penentuan dosis atau konsentrasi perlu dipertimbangkan dengan baik agar dapat memberikan pengaruh yang signifikan.

Diantara berbagai ektrak tanaman yang diuji menunjukkan bahwa ekstrak bawang merah memberikan pengaruh yang lebih baik terhadap semua komponen yang diamati. Ekstrak bawang merah kaya akan auksin sebagaimana dikemukakan oleh Kusdijanto (1998) bahwa perasan bawang merah mengandung zat pengatur tumbuh yang mempunyai peranan mirip Asam Indol Asetat (IAA). Selanjutnya menurut Muswita (2011) bahwa ekstrak bawang merah dapat digunakan sebagai hormon perangsang pertumbuhan tanaman pengganti auksin sintetik. Hormon 
tumbuh yang terkandung dalam bawang merah adalah auksin dan giberelin.

Sedangkan menurut Rahayu dan Berlian (1999), umbi bawang merah mengandung vitamin B1, Thiamin, riboflavin, asam nikotinat, serta ZPT auksin dan rhizokalin yang dapat merangsang pertumbuhan akar. Marfirani et al. (2014), menyatakan bahwa pada bawang merah terdapat senyawa yang disebut allin yang kemudian akan berubah menjadi senyawa thiosulfinat seperti allicin. Allicin dengan thiamin (vitamin $\quad$ B) membentuk allithiamin yang memperlancar metabolisme pada jaringan tumbuhan.

Dari serangkaian kandungan dalam ekstrak bawang merah menunjukkan adanya potensi untuk digunakan sebagai pemacu pertumbuhan pada setek tanaman lada. Hal ini terlihat dalam hasil penelitian bahwa ekstrak bawang merah dapat memacu pertumbuhan dan perkembangan setek tanaman lada, yakni waktu bertunas, jumlah tunas, panjang tunas, jumlah daun, luas daun, panjang akar, volume akar dan persentase setek hidup jika dibadingkan dengan ekstrak daun kelor dan sargassum.

Hasil ini sesuai dengan Siswanto, Sekta dan Romeida (2010) menunjukkan bahwa pemberian bawang merah dengan konsentrasi $500 \mathrm{~g} / \mathrm{L}$ dan lama perendaman
12 jam memberikan hasil terbaik untuk pertumbuhan panjang tunas, jumlah daun, tingkat kehijauan daun, dan bobot kering tunas pada setek lada panjang.

Dukungan hasil penelitian tentang ekstraksi bawang merah ditunjukkan oleh Purwitasari (2004) bahwa pemberian perasan bawang merah dengan konsentrasi $60 \%$ memberikan hasil optimum terhadap berat kering akar dan tinggi tanaman krisan. Sedangkan dengan konsentrasi $80 \%$ memberikan hasil yang optimum terhadap panjang akar tanaman krisan. Selanjutnya Setyowati (2004), menunjukkan pemberian ekstrak bawang merah konsentrasi $75 \%$ dapat meningkatkan panjang akar, jumlah tunas dan panjang tunas setek mawar. Alimuddin, Syamsiah dan Ramli (2017), bahwa pemberian ekstrak bawang merah pada konsentrasi $70 \%$ berpengaruh pada panjang akar, jumlah akar, berat basah akar dan berat kering akar pada setek batang bawah mawar (Rosa sp).

Dalam ekstrak bawang merah mengandung auksin dan senyawa organik yang dapat memacu pembelahan sel, pemanjangan sel, pembentukan akar, menghambat pertumbuhan tunas aksilar dan tunas adventif (Hopkins dan Hunner. 2004). Campbell (2003), menyatakan bahwa auksin tidak hanya memacu 
pemanjangan batang tetapi juga memacu pertumbuhan seluruh bagian tumbuhan termasuk akar dan daun. Namun demikian, berdasarkan hasil penelitian ini penggunaan berbagai ekstrak tanaman sebagai sumber hormon tumbuh memperlihatkan respon yang berbeda terhadap komponen pertumbuhan tanaman lada.

\section{KESIMPULAN}

1. Ekstrak tanaman berpotensi digunakan sebagai sumber zat pengatur tumbuh dalam meningkatkan pertumbuhan dan perkembangan setek tanaman lada.

2. Efektivitas hormon tumbuh Growtone lebih baik dibandingkan ekstrak tanaman (air kelapa, bawang merah, daun kelor, sargassum) dan urine sapi dalam merespon pertumbuhan setek tanaman lada.

3. Ekstrak bawang merah (75\%) berpotensi dijadikan sebagai sumber hormon tumbuh dalam perbaikan pertumbuhan dan perkembangan setek tanaman lada.

\section{TERIMA KASIH}

Terima kasih disampaikan kepada Universitas Muslim Indonesia dalam hal ini LP2S UMI dan Fakultas Pertanian/Program Studi Agroteknologi atas bantuan dan kerjasama dalam pelaksanaan penelitian ini.

\section{DAFTAR PUSTAKA}

Alimuddin, Syamsiah, M., dan Ramli. 2017. Aplikasi Pemberian Ekstrak bawang Merah (Allium cepa L.) Terhadap Pertumbuhan Akar Stek Batang Bawah Mawar (Rosa sp) Varietas Malltic. Jurnal Agroscience Vol. 7 No. 1.

Amanah, S. 2009. Pertumbuhan Bibit Stek Lada (Piper nigrum Linnaeus) Pada Beberapa Macam Media dan Konsentrasi Auksin. [Skripsi]. Universitas Sebelas Maret Surakarta.

Basmal, J. 2009. Prospek pemanfaatan rumput laut sebagai bahan pupuk organik. Squalen 4(1): 1-8.

Bukori. 2011. Uji Pemberian Growtone dan Plant Catalys 2006 pada Setek Tanaman Buah Naga (Hylocereus costaricensis). Universitas Pekan Riau. 19 halaman.

Campbell, N.A., Reece, J.B., dan Mitchell, L.G. 2003. Biologi. Jilid 2. Edisi Kelima. Alih Bahasa: Wasmen. Jakarta: Penerbit Erlangga.

Emongor, V.E. 2015. Effects of Moringa (Moringa oleifera) leaf extract on growth, yield and yield components of snap beans (Phaseolus vulgaris). British Journal of Applied Science and Technology. 6(2):114-122.

Hopkins, G.W. and N.P.A. Hunner. 2004. Introduction to Plant Physiology. Fourth edition. John wiley \& Sons, Inc, United States of America.

Kusdijanto, E. 1998. Peran konsentrasidan perbandingan campuranair kelapa dan homogenatebawang merah terhadappertumbuhan awal stekbeberapa kultivar jeruk (Citrus sp). [Skripsi] Jurusan Agronomi Fakultas pertanian Universitas Jember. Jember. 
Kusumo, S. 1990. Zat Pengatur Tumbuh. Yasaguna. Jakarta.

Maretza, D. T. 2009. Pengaruh Dosis Ekstrak Rebung Bambu Betung (Dendrocalamus asper Backer ex Heyne) Terhadap Pertumbuhan Semai Sengon (Paraserianthes falcataria (L.) Nielsen). Departemen Silvikultur Fakultas Kehutanan. Institut Pertanian Bogor. Bogor.

Maryani, Y dan Zamroni. 2005. Pengganda-an tunas krisan melalui kultur jaringan. Ilmu Pertanian. Vol 12(1): 51-5.

Murniati dan Zuhry, E .2002. Peranan giberelin terhadap perkecambahan benih kopi robusta tanpa kulit. Jurnal Sagu, vol 1(1):1-5.

Muswita. 2011. Pengaruh KonsentrasiBawang Merah (Allium Cepa L.)Terha-dap Pertumbuhan Setek Gaharu (Aquilaria malaccencisOken). Universitas Jambi Seri Sains volume 13(1):63-68.

Paulina. 2012. Optimasi Pertumbuhan Stek Apel. [Skripsi]. Program Studi Agroteknologi. Fakultas Pertanian, Universitas Wisnuwardhana Malang.

Purwitasari, Wiwit. 2004. Pengaruh Perasan Bawang Merah (Allium $\begin{array}{lll}\text { ascalonicum } & \text { L.) } & \text { Terhadap }\end{array}$ Pertumbuhan Akar Stek Pucuk Krisan (Chrysanthemum sp). [Undergraduate Thesis] FMIPA Undip.

Rahayu, E dan N. Berlian. 1999. Pedoman Bertanam Bawang Merah. Penebar Swadaya. Jakarta.

Siswanto, U., N. D. Sekta, dan A.Romeida. 2010. Penggunaanauksin dan sitokinin alami pada pertumbuhan bibit lada panjang (Piper retrofractumvah L.). Tumbuhan Obat Indonesia, vol 3 (2) : 128-132.

Statistik perkebunan Indonesia.2015. Produksi Lada Nasional. Jakarta:Direktorat Jenderal Perkebunan.

Trisna, N., Husain, U., dan Irmasari. 2013. Pengaruh Berbagai Jenis Zat Pengatur TumbuhTerhadap Pertumbuhan Stump Jati (Tectona grandis). Jurnal Warta rimba. Vol 1(1) : 1-9.

Wahyudi, A. 2016. Peran Bakteri Fotosintetik Synechoccus sp dan Ekstrak Rumput Laut Dalam Meningkatkan Pertumbuhan Tanaman Kedelai Pada Berbagai Komposisi Nutrisi Di Lahan Tegalan. [Skripsi]. Universitas Jember.

Watijo. 2007. Uji Beberapa Jenis Zat Pengatur Tumbuh pada Setek Lada (PipernigrumL.) Asal Sulur Panjat dan Sulur Gantung. [Skripsi] STIPER DharmaWacana Metro Lampung. 11 halaman.

Wattimena, G. A. 2000. Pengembangan Propagul Kentang Bermutu dan Kultivar Kentang Unggul dalam Mendukung Peningkatan Produksi Kentang di Indonesia. Orasi Ilmiah Guru Besar Tetap Ilmu Hortikultura. Fakultas Pertanian Institut Pernian Bogor.

Yunita, R. 2011. Pengaruh Pemberian Urine Sapi, Air Kelapa, dan Rootone F terhadap Pertumbuhan Setek Tanaman Markisa (Passiflora Edulis Var.Flavicarpa). Universitas Solok. 7 halaman. 